\title{
The Incidence of Metabolic Syndrome in Obese Czech Children: the Importance of Early Detection of Insulin Resistance Using Homeostatic Indexes HOMA-IR and QUICKI
}

\author{
D. PASTUCHA ${ }^{1 *}$, R. FILIPČÍKOVÁ ${ }^{2 *}$, D. HORÁKOVÁ ${ }^{3}$, L. RADOVÁ $^{4}$, Z. MARINOV $^{5}$, \\ J. MALINČÍKOVÁ ${ }^{1}$, M. KOCVRLICH ${ }^{1}$, S. HORÁK ${ }^{1}$, M. BEZDIČKOVÁ ${ }^{2}$, M. DOBIÁŠ \\ * These authors contributed equally to this work
}

${ }^{1}$ Department of Sports and Exercise Medicine, Faculty of Medicine and Dentistry, Palacky University Olomouc, Olomouc, ${ }^{2}$ Department of Anatomy, Faculty of Medicine and Dentistry, Palacky University Olomouc, Olomouc, ${ }^{3}$ Department of Preventive Medicine, Faculty of Medicine and Dentistry, Palacky University Olomouc, Olomouc, ${ }^{4}$ Laboratory of Experimental Medicine, Institute of Molecular and Translational Medicine, Faculty of Medicine and Dentistry, Palacky University Olomouc, Olomouc, ${ }^{5}$ Outpatient Clinic for the Treatment of Child Obesity, University Hospital Prague Motol, ${ }^{6}$ Department of Forensic Medicine and Medical Law, Faculty of Medicine and Dentistry, Palacky University Olomouc, Olomouc, Czech Republic

Received July 31, 2012

Accepted November 28, 2012

On-line March 14, 2013

\section{Summary}

Common alimentary obesity frequently occurs on a polygenic basis as a typical lifestyle disorder in the developed countries. It is associated with characteristic complex metabolic changes, which are the cornerstones for future metabolic syndrome development. The aims of our study were 1 ) to determine the incidence of metabolic syndrome (based on the diagnostic criteria defined by the International Diabetes Federation for children and adolescents) in Czech obese children, 2) to evaluate the incidence of insulin resistance according to HOMA-IR and QUICKI homeostatic indexes in obese children with and without metabolic syndrome, and 3) to consider the diagnostic value of these indexes for the early detection of metabolic syndrome in obese children. We therefore performed anthropometric and laboratory examinations to determine the incidence of metabolic syndrome and insulin resistance in the group of 274 children with obesity (128 boys and 146 girls) aged 9-17 years. Metabolic syndrome was found in 102 subjects (37\%). On the other hand, the presence of insulin resistance according to QUICKI $<0.357$ was identified in $86 \%$ and according to HOMA-IR $>3.16$ in $53 \%$ of obese subjects. This HOMA-IR limit was exceeded by $70 \%$ children in the $\mathrm{MS}(+)$ group, but only by $43 \%$ children in the MS $(-)$ group $(p<0.0001)$. However, a relatively high incidence of insulin resistance in obese children without metabolic syndrome raises a question whether the existing diagnostic criteria do not falsely exclude some cases of metabolic syndrome. On the basis of our results we suggest to pay a preventive attention also to obese children with insulin resistance even if they do not fulfill the actual diagnostic criteria for metabolic syndrome.

\section{Key words}

Obesity • Metabolic syndrome • HOMA-IR • QUICKI • Children • Adolescents

\section{Corresponding author}

Radka Filipčíková, Department of Anatomy, Faculty of Medicine and Dentistry, Palacký University Olomouc, Hněvotínská 3, Czech Republic. E-mail: radka.filipcikova@upol.cz

\section{Introduction}

Common alimentary obesity frequently occurs on a polygenic basis as a typical lifestyle disorder in countries of the developed world. It is characterized by the gradual onset and the development of typical complex metabolic changes. Multiple genetic polymorphisms, 
which are responsible for polygenic hereditability of obesity, result in the alterations of physiological regulatory mechanisms and the prevalence of accumulation mechanisms over energy expenditure. Adipose tissue is the largest endocrine organ in the human body, and when its excessive multiplication occurs, gradual but extensive metabolic changes take place (Horáková et al. 2010). Complex metabolic changes, acting in a mutually linked manner, are the basic cornerstones for the development of metabolic syndrome (MS) that is characterized by insulin resistance, endothelial dysfunction and dyslipidemia. However, the adult phenotypes - insulin resistance, type 2 diabetes and hypertension - could be the consequences of an insulinresistant genotype, which manifest already in utero and develop in childhood (Kuneš and Zicha 2009, Kuneš et al. 2012). Insulin resistance development leads to the early onset of type 2 diabetes and accelerates the onset of hypertension which is later accompanied by various cardiovascular complications including the atherosclerosis (Lobstein and Jackson-Leach 2006). In recent years, obesity and metabolic syndrome have become the greatest hurdle in preventive cardiology (Ludwig 2007).

The criteria for metabolic syndrome keep developing and even the original model (Reaven 1988, 1993) is gradually being abandoned. The generally applicable definition was stipulated for the first time in 1998 by the World Health Organization (WHO 1999), and further modified in 2001 according to Adult Treatment Panel III (NCEP/ATPIII 2001). The current definition MS in adult patients was established by the International Diabetes Federation (IDF) in 2005 (Ford 2005). In 2007, the IDF criteria were modified for the pediatric population, in which MS is defined from 10 to 16 years of age in relation to the 90th BMI percentile (Zimmet et al. 2007). However, the MS criteria set for the adult population might be inadequate for the pediatric population (Simmons et al. 2010). Increased fasting glucose as a criterion of MS loses its preventive character in the pediatric population because it becomes an indicator of organ impairment. Therefore the impairment of glucose tolerance in children must be verified by means of oral glucose tolerance test.

For adult patients, the so-called euglycemic "clamp" method is considered to be the most appropriate approach, but this examination is unacceptably invasive for children, it is performed under non-physiological conditions, and this method is very demanding for both the physicians and patients (Marinov and Pastucha 2012). The same is also true for some simplified methods that were later developed. The most frequently used is the socalled Bergman's minimal model (Bergman 1979), which is based upon an intravenous glucose tolerance test. This technique, which evaluates the dependence between the plasma concentrations of glucose and insulin, provides the so-called insulin sensitivity index (SI). This index correlates well with the euglycemic clamp (Katz et al. 2000). The impairment of the homeostatic relation between plasma insulin and glucose concentrations is a symptom of insufficient insulin efficiency that can be evaluated using the so-called homeostatic model for insulin resistance assessment (HOMA-IR) and quantitative insulin sensitivity check index (QUICKI). Both indexes are derived from fasting plasma glucose and fasting plasma insulin concentrations and they correlate reasonably with the euglycemic clamp technique (Rossner et al. 2010). Our pilot study (Pastucha et al. 2010), which evaluated the possibility of early detection of insulin resistance in obese or hypertensive children, disclosed significant differences in HOMA-IR or QUICKI indexes in these two groups as compared to healthy control population.

The aim of our study was not only to determine the incidence of metabolic syndrome in Czech obese children according the diagnostic IDF criteria, but also to consider the diagnostic value of early detection of insulin resistance (revealed by HOMA-IR and QUICKI homeostatic indexes) in obese children without metabolic syndrome.

\section{Methods}

A total of 274 children aged 9-17 years were enrolled in the study. These children are also being monitored at the Obesitology Department at the Department of Exercise Medicine and Cardiovascular Rehabilitation at the University Hospital, and the Faculty of Medicine and Dentistry, Palacký University in Olomouc. There were 146 boys with a median age of 12 years, and 128 girls with the same median age. Children were referred by their pediatricians to the Obesitology Department in order to reduce their abnormal body weight. Owing to the stipulated objectives of this work, only children with body mass index (BMI) over 97th percentile (Vígnerová et al. 2005) were monitored within the frame of this study. For each child, the following parameters were determined: blood 
pressure measured by a standard mercury tonometer, using a stethoscope placed over the brachial artery for auscultation of pulse, according to the Task Force Report on High Blood Pressure in Children and Adolescents (NHBPEP 1996), waist circumferences were measured at a level midway between the lowest rib and the iliac crest and hip circumferences were measured at its widest part of the hip, BMI percentile, as well as serum concentrations of glucose, insulin, total cholesterol, triacylglycerols, high-density lipoproteins (HDL) and low-density lipoproteins (LDL) cholesterol. On the basis of fasting plasma insulin and glucose levels homeostasis model assessment of insulin resistance (HOMA-IR) and quantitative insulin-sensitivity check (QUICKI) indexes were calculated. HDL-cholesterol, LDL-cholesterol, blood glucose and insulin were measured on a biochemical analyzer ILAB-600 (Instrumentation Laboratory, Lexington, MA, USA), while using sets from the Bio Vendor company. These measurements were carried out at the Department of Clinical Biochemistry in University Hospital in Olomouc (according to ISO 9001: 2000).

Homeostatic indexes of insulin resistance HOMA-IR and QUICKI were calculated according to the formulae of Katz et al. (2000):

HOMA-IR = fasting insulin $(\mu \mathrm{IU} / \mathrm{ml}) \quad \mathrm{x}$ fasting blood glucose $(\mathrm{mmol} / \mathrm{l}) / 22.5$

QUICKI $=1 /[\log$ fasting insulin $(\mu \mathrm{IU} / \mathrm{ml})+\log$ fasting blood glucose $(\mathrm{mg} / 100 \mathrm{ml})]$,

i.e. $1 /[\log$ fasting insulin $(\mu \mathrm{IU} / \mathrm{ml})+\log$ fasting blood glucose (mmol/l) x 18.182]

The group of children with metabolic syndrome (MS+) included those who fulfilled the IDF criteria (Zimmet et al. 2007), but some criteria (BMI percentile) were used according to Weiss et al. (2004). First of all, there are no data for waist circumference for Czech children population so that we had to use the 97th BMI percentile (according to sex and age). Furthermore, we also used the 95th percentile as the limit for blood pressure. MS was defined as having at least three out of the five following criteria: 1) obesity, BMI above the 97th percentile for age and sex, 2) abnormal glucose homeostasis, such as fasting glucose above $5.6 \mathrm{mmol} / \mathrm{l}$, 3) hypertension, systolic blood pressure above the 95th percentile for age and sex according to the American
Group for Children Hypertension (NHBPEP 1996), 4) dyslipidemia such as triacylglycerols above $1.2 \mathrm{mmol} / \mathrm{l}$ (in children under 10 years of age) or above $1.5 \mathrm{mmol} / \mathrm{l}$ (in children above 10 years of age), and 5) low HDLcholesterol below $0.9 \mathrm{mmol} / \mathrm{l}$. Children not fulfilling the MS diagnostic criteria were included to the group without metabolic syndrome (MS-).

For statistical analysis of the data, the software Statistica 8 (StatSoft, Inc.) was used. Comparative analysis between MS+ and MS- groups was carried out using the Mann-Whitney test. $\mathrm{P}<0.05$ level was considered to be statistically significant.

\section{Results}

The clinical characteristics of the studied population of Czech obese children are shown in Table 1. There were no major sex differences except of greater waist circumference in girls.

Symptoms of insulin resistance at QUICKI $<0.357$ were identified in $86 \%$ and at HOMA-IR $>3.16$ in $53 \%$ of the subjects. In the MS+ group, HOMA-IR limit was exceeded in $70 \%$ children, whereas in the MSgroup it was found only in $43 \%$ children $(p<0.0001)$. Metabolic syndrome was found in 102 (37\%) of our subjects. MS occurrence was higher in boys (43\%) than in girls $(31 \%)$.

The comparison of the clinical and laboratory features between the groups with $(\mathrm{MS}+)$ or without metabolic syndrome (MS-) is shown in Table 2. The median BMI, waist circumference, and systolic and diastolic blood pressure were higher in the MS+ group. Serum levels of triacylglycerols were higher, and HDL-C levels were lower in the group with MS than in those without MS. Basal insulin and glucose levels as well as HOMA-IR and QUICKI were also significantly different between MS+ and MS- groups (Table 2).

\section{Discussion}

Childhood-onset obesity, left untreated, is known to significantly affect morbidity and mortality in adulthood (Daniels et al. 2005). In the Czech Republic, $50 \%$ of the adult population are currently struggling with the overweight and $20 \%$ are obese (Lajka et al. 2006). In the pediatric population, the incidence of common obesity is increasing steadily and currently it accounts for $95-99 \%$ of obesity cases, while the level of pathognomonic obesity remains practically unchanged 
Table 1. The clinical characteristics of the studied population of Czech obese children.

$\begin{array}{llll}\begin{array}{l}\text { All children } \\ (\text { median, } \min / \max )\end{array} & \begin{array}{l}\text { Girls } \\ (\text { median, } \min / \max )\end{array} & \begin{array}{l}\text { Boys } \\ (\text { median, } \min / \mathbf{m a x})\end{array} & \begin{array}{l}\text { p-value } \\ (\text { Mann-Whitney }) \\ \text { boys vs. girls }\end{array}\end{array}$

\begin{tabular}{lllll}
\hline$N$ & 274 & 128 & 146 & \\
Age (years) & $12(9-17.5)$ & $12(9-17.5)$ & $12(10-17)$ & n.s. \\
SBP $(\mathrm{mm} \mathrm{Hg})$ & $120(85-170)$ & $120(85-155)$ & $120(100-170)$ & $<0.04$ \\
DBP $(\mathrm{mm} \mathrm{Hg})$ & $75(40-105)$ & $72.5(40-105)$ & $75(50-105)$ & $<0.04$ \\
TC $(\mathrm{mmol} / \mathrm{l})$ & $4.56(2.55-10.15)$ & $4.57(3.26-6.78)$ & $4.54(2.55-10.15)$ & n.s. \\
HDL (mmol/l) & $1.14(0.5-2.15)$ & $1.16(0.5-1.92)$ & $1.12(0.57-2.15)$ & n.s. \\
LDL (mmol/l) & $2.5(0.73-11.44)$ & $2.52(0.92-4.9)$ & $2.4(0.73-11.44)$ & n.s. \\
TG $(\mathrm{mmol} / \mathrm{l})$ & $1.2(0.31-4.92)$ & $1.17(0.46-3.6)$ & $1.24(0.31-4.92)$ & n.s. \\
Glucose $(\mathrm{mmol} / \mathrm{l})$ & $4.9(2.9-6.5)$ & $4.9(3.5-6)$ & $5(2.9-6.5)$ & n.s. \\
Insulin $(\mu \mathrm{IU} / \mathrm{ml})$ & $15.7(2-54)$ & $15.6(2-54)$ & $15.8(2-52.2)$ & n.s. \\
HOMA-IR & $3.35(0.26-14.85)$ & $3.40(0.37-12.72)$ & $3.31(0.26-14.85)$ & n.s. \\
QUICKI & $0.319(0.264-0.494)$ & $0.318(0.269-0.458)$ & $0.319(0.264-0.494)$ & n.s. \\
Waist $(\mathrm{cm})$ & $84(50-135)$ & $80(52-128)$ & $87(50-135)$ & $<0.0003$ \\
Hip $(\mathrm{cm})$ & $90(52-145)$ & $88(60-145)$ & $92(52-130)$ & n.s. \\
\hline
\end{tabular}

SBP - systolic blood pressure, DPB - diastolic blood pressure, TC - total cholesterol, glucose - fasting blood glucose level, insulin fasting insulin level, HDL - high density lipoproteins, LDL - low density lipoproteins, TG - triacylglycerols, HOMA-IR - homeostasis model assessment of insulin resistance, QUICKI - quantitative insulin sensitivity check index, waist - waist circumference, hip - hip circumference.

Table 2. The incidence of metabolic syndrome in the studied population of Czech obese children and the differences in clinical characteristics between both studied subpopulations (MS+ vs. MS-).

\begin{tabular}{|c|c|c|c|c|}
\hline & $\begin{array}{l}\text { All children } \\
\text { (median, } \min / \text { max) }\end{array}$ & $\begin{array}{l}\text { MS+ } \\
\text { (median, } \min / \text { max) }\end{array}$ & $\begin{array}{l}\text { MS- } \\
\text { (median, } \min / \text { max) }\end{array}$ & $\begin{array}{l}\text { p-value } \\
\text { (MS+ vs. MS-) }\end{array}$ \\
\hline Gender $(M / F)$ & $274(128 / 146)$ & $102(56 / 46)$ & $172(90 / 82)$ & n.s. \\
\hline Age (years) & $12(9-17.5)$ & $13(9.6-17.5)$ & $12(9-17.3)$ & $<0.0001$ \\
\hline Body weight (kg) & $69.05(32.5-133.8)$ & $80.55(33-133.8)$ & $64.35(32.5-127.4)$ & $<0.000001$ \\
\hline $\mathrm{SBP}(\mathrm{mm} \mathrm{Hg})$ & $120(85-170)$ & $135(100-170)$ & $120(85-145)$ & $<0.000001$ \\
\hline$D B P(m m ~ H g)$ & $75(40-105)$ & $80(60-105)$ & $70(40-100)$ & $<0.000001$ \\
\hline$T C(\mathrm{mmol} / \mathrm{l})$ & $4.56(2.55-10.15)$ & $4.95(2.98-10.15)$ & $4.40(2.55-6.58)$ & $<0.00001$ \\
\hline$H D L(\mathrm{mmol} / \mathrm{l})$ & $1.14(0.5-2.15)$ & $0.98(0.5-1.91)$ & $1.23(0.57-2.15)$ & $<0.000001$ \\
\hline$L D L(\mathrm{mmol} / \mathrm{l})$ & $2.5(0.73-11.44)$ & $2.68(1.20-11.44)$ & $2.41(0.73-4.90)$ & $<0.03$ \\
\hline$T G(\mathrm{mmol} / \mathrm{l})$ & $1.2(0.31-4.92)$ & $1.89(0.31-4.92)$ & $1.03(0.40-3.36)$ & $<0.000001$ \\
\hline Glucose $(\mathrm{mmol} / \mathrm{l})$ & $4.9(2.9-6.5)$ & $5.1(3.9-6.4)$ & $4.9(2.9-6.5)$ & $<0.0002$ \\
\hline Insulin $(\mu I U / m l)$ & $15.7(2-54)$ & $21(2-52.2)$ & $13(2-54)$ & $<0.000001$ \\
\hline$H O M A-I R$ & $3.35(0.26-14.85)$ & $4.80(0.37-14.85)$ & $3.80(0.26-12.72)$ & $<0.000001$ \\
\hline QUICKI & $0.319(0.264-0.494)$ & $0.304(0.264-0.458)$ & $0.327(0.269-0.494)$ & $<0.000001$ \\
\hline Waist (cm) & $84(50-135)$ & $92(50-135)$ & $81(52-134)$ & $<0.000001$ \\
\hline Hip (cm) & $90(52-145)$ & $100(52-145)$ & $87(59-128)$ & $<0.000001$ \\
\hline
\end{tabular}

SBP - systolic blood pressure, DPB - diastolic blood pressure, TC - total cholesterol, glucose - fasting blood glucose level, insulin fasting insulin level, HDL - high density lipoproteins, LDL - low density lipoproteins, TG - triacylglycerols, HOMA-IR - homeostasis model assessment of insulin resistance, QUICKI - quantitative insulin sensitivity check index, waist - waist circumference, hip - hip circumference. 
(Marinov et al. 2012). According to the study "Lifestyle and Obesity 2005" (Czech Society for the Study of Obesity) (Lajka et al. 2006, Vígnerová et al. 2006) about $20 \%$ of children aged 6 to 12 years and $11 \%$ of children aged 13 to 17 years were already overweight or obese. In the group aged 6 to 12 years, $10 \%$ of children were overweight and $10 \%$ were obese. The highest percentage of children with obesity (18\%) was at the age of 7 years, which can be related to the lifestyle change associated with the beginning of school. The data for the adolescent population are somewhat more favorable, because in the age group from 13 to 17 years there were only $6 \%$ overweight children and $5 \%$ obese children (Dagres and Anastasiou-Nana 2010, Marinov and Pastucha 2012).

Metabolic syndrome is highly prevalent within the adult population worldwide and is becoming a serious problem in the pediatric population as well (Kelishadi et al. 2007). Unfortunately, there is no standard definition of metabolic syndrome for the use in pediatric populations. In a recent review, Ford and $\mathrm{Li}$ (2008) analyzed 27 articles with 40 definitions of MS in children. The prevalence of MS among children and adolescents varies according to the definitions and the age. Some studies estimated MS prevalence as high as $30-50 \%$ in overweight/obese children and adolescents (Cook et al. 2003, Weiss et al. 2004). The prevalence study on a cohort of U.S. overweight/obese adolescents, in which ATP III criteria were used (de Ferranti et al. 2004), yielded similar MS prevalence (31\%) as our study. Weiss et al. (2004) reported $27 \%$ incidence of MS when a large cohort of obese children with a wide range of age was analyzed according to ATP III criteria (NCEP/ATPIII 2001). However, the subsequent analysis of this multiracial cohort according to the same criteria, that were used our study, yielded a substantially higher MS incidence, which correlated with the degree of obesity. The overall prevalence of the metabolic syndrome was $39 \%$ in moderately obese subjects and $50 \%$ in severely obese subjects (Weiss et al. 2004). These results are in agreement with the results of our work because both studies utilized identical modification of IDF criteria.

Insulin resistance is the most common metabolic alteration related to obesity and it represents an important link between obesity and other metabolic or cardiovascular complications (Sinha et al. 2002). Altered insulin sensitivity is thought to play a critical role in the pathogenesis of type 2 diabetes among children (Pastucha et al. 2010). The review by Ford and $\mathrm{Li}$ (2008) revealed that 12 of 27 studies included hyperinsulinemia or increased HOMA-IR as one of the criteria for metabolic syndrome. Thus the study by da Silva et al. (2005) compared the MS incidence in children with normal body weight, overweight and obesity. MS incidence was $26 \%$ in obese children in which the closest correlation with HOMA-IR values was observed. The importance of HOMA-IR index as an adequate tool for determination of insulin resistance in obese children was further supported by Makni et al. (2012). They reported in both sexes that HOMA-AD and HOMA-IR indexes correlated better with the majority of MS components than the adiponectin/leptin ratio. Sharma et al. (2011) also found that HOMA-IR is a stronger indicator of MS in children than fasting blood glucose. Thus our study further supports the validity of HOMA-IR index as an adequate tool for determining insulin resistance in obese children. Our pilot study revealed HOMA-IR value 4.58 in obese children, 2.75 in hypertensive children and 1.80 in healthy controls (Pastucha et al. 2010).

In conclusion, our study confirmed a high incidence of metabolic syndrome (37\%) in a group of Czech children with obesity. According to the HOMA and QUICKI indexes, insulin resistance was identified in $53 \%$ obese children, $70 \%$ of which were in the group of children with metabolic syndrome. However, insulin resistance was also detected among children who did not fulfill the criteria for metabolic syndrome. When we compared the groups of obese children with and without metabolic syndrome, we found a more significant difference in the value of HOMA-IR and QUICKI indexes than in the value of fasting blood glucose. We therefore believe that the insulin resistance parameters should be included among the MS diagnostic criteria for children to reduce the number of cases with falsely negative diagnosis of metabolic syndrome. We also suggest to focus the attention for children with insulin resistance even if they did not fulfill the criteria for metabolic syndrome because the early onset of preventive measures might be important for further metabolic syndrome development.

\section{Limitations of the study}

In our future research we would like to subdivide our cohort of obese children according to their age into pre- and postpubertal groups. We also intend to perform a long-term follow-up of obese MS+ and MSchildren from this cohort. 


\section{Conflict of Interest}

There is no conflict of interest.

\section{Acknowledgements}

This study was supported by grant NT 11098-4/2010 and the infrastructural part of this project (Institute of Molecular and Translational Medicine) was supported by the Operational Program of Research and Development for Innovations (project CZ.1.05/2.1.00/01.0030).

\section{References}

BERGMAN RN, IDER YZ, BOWDEN CR, COBELLI C: Quantitative estimation of insulin sensitivity. Am J Physiol 236: E667-E677, 1979.

COOK S, WEITZMAN M, AUINGER P, NGUEN M, DIETZ WH: Prevalence of a metabolic syndrome phenotype in adolescents: findings from the third National Health and Nutrition Examination Survey, 1988-1994. Arch Pediatr Adolesc Med 157: 821-827, 2003.

DA SILVA RC, MIRANDA WL, CHACRA AR, DIB SA: Metabolic syndrome and insulin resistance in normal glucose tolerant Brazilian adolescents with family history of type 2 diabetes. Diabetes Care 28: 716-718, 2005.

DAGRES N, ANASTASIOU-NANA M: Atrial fibrillation and obesity: an association of increasing importance. $J \mathrm{Am}$ Coll Cardiol 55: 2328-2329, 2010.

DANIELS SR, ARNETT DK, ECKEL RH, GIDDING SS, HAYMAN LL, KUMANYIKA S, ROBINSON TN, SCOTT BJ, JEOR S, WILLIAMS CL: Overweight in children and adolescents: pathophysiology, consequences, prevention and treatment. Circulation 111: 1999-2012, 2005.

DE FERRANTI SD, GAUVREAU K, LUDWIG DS, NEUFELD EJ, NEWBURGER JW, RIFAI N: Prevalence of the metabolic syndrome in American adolescents: findings from the Third National Health and Nutrition Examination Survey. Circulation 110: 2494-2497, 2004.

FORD ES: Prevalence of the metabolic syndrome defined by the international diabetes federation among adults in the U.S. Diabetes Care 28: 2745-2749, 2005.

FORD ES, LI C: Defining the metabolic syndrome in children and adolescents: will the real definition please stand up? J Pediatr 152: 160-164, 2008.

HORÁKOVÁ D, STEJSKAL D, PASTUCHA D, MUCHOVÁ L, JANOUT V: Potential markers of insulin resistance in healthy vs obese and overweight subjects. Biomed Pap Med Fac Univ Palacky Olomouc Czech Rep 154: 245-250, 2010.

KATZ A, NAMBI SS, MATHER K, BARON AD, FOLLMANN DA, SULLIVAN G, QUON MJ: Quantitative insulin sensitivity check index: a simple, accurate method for assessing insulin sensitivity in humans. $J$ Clin Endocrinol Metab 85: 2402-2410, 2010.

KELISHADI R, ARDALAN G, ADELI K, MOTHAGIAN M, MAJDZADECH R, MAHOOD-ARABI MS, DELAVARI A, RIAZI MM, NAMAZI R, RAMEZANI MA; CASPIAN STUDY GROUP: Factor analysis of cardiovascular risk clustering in pediatric metabolic syndrome: CASPIAN study. Ann Nutr Metab 51: 208-215, 2007.

KUNEŠ J, ZICHA J: Developmental windows and environment as important factors in the expression of genetic information: a cardiovascular physiologist's view. Clin Sci 111: 295-305, 2006.

KUNEŠ J, KADLECOVÁ M, VANĚČKOVÁ I, ZICHA J: Critical developmental periods in the pathogenesis of hypertension. Physiol Res 61 (Suppl 1): S9-S17, 2012.

LAJKA J, KUNEŠOVÁ M, HAINER V: Lifestyle and Obesity - Final Report of the Project of Ministry of Health of the Czech Republic. STENMARK, Prague, 2006.

LOBSTEIN T, JACKSON-LEACH R: Estimated burden of paediatric obesity and co-morbidities in Europe. Part 2. Numbers of children with indicators of obesity-related disease. Int J Pediatr Obes 1: 33-41, 2006.

LUDWIG DS: Childhood obesity - the shape of things to come. N Engl J Med 357: 2325-2327, 2007.

MAKNI E, MOALLA W, LAC G, AOUICHAOUI C, CANNON D, ELLOUMI M, TABKA Z: The Homeostasis Model Assessment-adiponectin (HOMA-AD) is the most sensitive predictor of insulin resistance in obese children. Ann Endocrinol (Paris) 73: 26-33, 2012. 
MARINOV Z, PASTUCHA D: Simple childhood obesity and its metabolic consequences. (in Czech) Čas lék čes 151: 135-140, 2012.

MARINOV Z, PASTUCHA D ET AL.: Practical Child Obesitology. (in Czech) Grada Publishing, Prague, 2012, pp 36-52.

NCEP/ATPIII: Executive Summary of the Third Report of the National Cholesterol Education Program (NCEP) Expert Panel on Detection, Evaluation, and Treatment of High Blood Cholesterol in Adults (Adult Treatment Panel III). JAMA 285: 2486-2497, 2001.

NHBPEP: Update on the 1987 Task Force Report on High Blood Pressure in Children and Adolescents: a working group report from the National High Blood Pressure Education Program. National High Blood Pressure Education Program Working Group on Hypertension Control in Children and Adolescents. Pediatrics 98: 649658, 1996.

PASTUCHA D, TALAFA V, MALINČÍKOVÁ J, ČÍHALÍK C, HYJÁNEK J, HORÁKOVÁ D, JANOUT V: Obesity, hypertension and insulin resistance in childhood - a pilot study. Biomed Pap Med Fac Univ Palacky Olomouc Czech Rep 154: 77-82, 2010.

REAVEN GM: Role of insulin resistance in human disease. Diabetes 37: 1595-1607, 1988.

REAVEN GM: Role of insulin resistance in human disease (syndrome X): an expanded definition. Annu Rev Med 44: 121-131, 1993.

ROSSNER SM, NEOVIUS M, MATTSSON A, MARCUS C, NORGREN S.: HOMA-IR and QUICKI: decide on a general standard instead of making further comparisons. Acta Paediatr 99: 1735-1740, 2010.

SHARMA S, LUSTIG RH, FLEMING SE: Identifying metabolic syndrome in African American children using fasting HOMA-IR in place of glucose. Prev Chronic Dis 8: A64, 2011.

SIMMONS RK, ALBERTI KG, GALE EA, COLAGIURI S, TUOMILEHTO J, QIAO Q, RAMACHANDRAN A, TAJIMA N, BRAJKOVICH MI, BEN-NAKHI A, REAVEN G, HAMA SAMBO B, MENDIS S, ROGLIC G: The metabolic syndrome: useful concept or clinical tool? Diabetologia 53: 600-605, 2010.

SINHA R, FISH G, TAEGUE B, TAMBORLANE WV, BANYAS B, ALLEN K, SAVOYE M, RIEGER V, TAKSALI S, BARBETTA G, SHERVIN SR, CAPRIO S: Prevalence of impaired glucose tolerance among children and adolescents with marked obesity. $N$ Engl J Med 346: 802-810, 2002.

VÍGNEROVÁ J, RIEDLOVÁ J, BLÁHA P, KOBZOVÁ J, KREJČOVSKÝ L, BRABEC M, HRUŠKOVÁ M: National Anthropological Research of Children and Youth 2001. Czech Republic Final Results. (in Czech) PřF UK, SZÚ, Prague, 2006.

VÍGNEROVÁ J, HUMENÍKOVÁ L, BRABEC M, RIEDLOVÁ J, BLÁHA P: Long-term changes in body weight, BMI, and adiposity rebound among children and adolescents in the Czech Republic. Econom Human Biol 5: 409-425, 2007.

WEISS R, DZIURA J, BURGERT TS, TAMBORLANA WV, TAKSALI SE, YECKEL CW, ALLEN K, LOPES M, SAVOYE M, MORRISON J, SHERWIN RS, CAPRIO S: Obesity and the metabolic syndrome in children and adolescents. $N$ Engl J Med 350: 2362-2374, 2004.

WHO: Definition, Diagnosis and Classification of Diabetes Mellitus and Its Complications. Part 1: Diagnosis and Classification of Diabetes Mellitus. Department of Noncommunicable Disease Surveillance, Geneva, 1999, pp 31-33.

ZIMMET P, ALBERTI KG, KAUFMAN F, TAJIMA N, SILINK M, ARSLANIAN S, WONG G, BENNETT P, SHAW J, CAPRIO S: Metabolic syndrome in children and adolescents - an IDF consensus report. Pediatr Diabetes 8: 299-306, 2007. 